\title{
Influence of a Microwave Irradiation on the Swelling and Permeation Properties of a Nafion Membrane
}

\author{
V.M. Barragán ${ }^{1, *}$ and S. Muñoz ${ }^{2}$ \\ ${ }^{1}$ Department of Applied Physics I, Faculty of Physics, University Complutense of Madrid, 28040 Madrid, \\ Spain \\ ${ }^{2}$ Department of Applied Physics III, Faculty of Physics, University Complutense of Madrid, 28040 Madrid, \\ Spain
}

\begin{abstract}
The effect of a microwave irradiation at $2450 \mathrm{MHz}$ on the swelling and permeation properties of a Nafion membrane in water and methanol media has been studied. The influence of the irradiation power and the exposure time has been analyzed. The results found show that the irradiation hardly affects the membrane liquid uptake, but it affects the expansion properties of the membrane. The hydraulic permeability coefficient of the unmodified and the irradiated membranes has been experimentally determined. Higher hydraulic permeability has been obtained for the irradiated membranes in both water and methanol, but the degree of increment in permeability coefficient with microwave depends on kinds of permeation liquid. The results have been discussed considering the degradation effect occurring on the membrane hydrophobic matrix, which affects to the membrane elastic properties.
\end{abstract}

Keywords: Nafion membrane, microwave, hydraulic permeability, swelling, liquid uptake, water, methanol.

\section{INTRODUCTION}

Perfluorinate ionomer membranes are very interesting materials used in many applications as solid polymer electrolyte in fuel cells and other applications in electrochemistry and separation technologies. In all these applications, the behavior of the membrane is of the greatest importance to the viability and performance of the involved processes.

The well known perfluorosulfonate ionomer Nafion is typically the one more used as solid electrolyte in most polymer fuel cells, owing to good chemical and thermal resistance and ionic conductivity, and it has been the focus of a large number of studies [1]. The use of Nafion as proton exchange membrane (PEM) in direct methanol fuel cells is an important application of this membrane and its behavior in organic media, mainly alcohols, has been studied in a number of papers [1-6]. Despite its good qualities, the high methanol permeability and the hydration dependence of Nafion [7] make necessary to look for alternative polymer electrolytes. In this search, Nafion uses to be the reference membrane to compare the properties of the alternative membranes.

It is well known that the functional properties of polymeric exchange membranes are determined by their structure. The morphology of a hydrated PEM has a direct bearing on the ion and water transport

*Address correspondence to this author at the Department of Applied Physics I, Faculty of Physics, University Complutense of Madrid, 28040 Madrid, Spain; Fax: +34 9139451 91; E-mail: vmabarra@ucm.es characteristic of the membrane and many works have been focused on the study of Nafion structure in relation to the membrane swelling properties [8-15]. Water management is a significant challenge for polymer fuel operation. To keep the membrane fully hydrated, it is essential to increase the pressure in the fuel cell above the water vapor pressure. The amount of water sorption of the membrane is determined by a balance between the membrane swelling pressure and the applied pressure from the electrode pressing against the membrane. A central challenge in the design of new PEMs is thus an analysis of the swelling and permeation characteristics needed to achieve high proton conductivity.

Different approaches have been attempted to develop new materials. One of the alternatives is the use of different radiations to modify Nafion membranes [16-18].

Studies show that it is possible to give rise to chemical and structural changes in the membranes by means of irradiations, obtaining different effects depending on the type and conditions of the irradiation [16-30]. Microwave has been widely used for heating and drying materials. In particular, it has been industrially applied for vulcanization in rubbers, foam processing, polymerization-solidification, adhesions and so on [31-32]. Studies carried out show that polymer properties can be affected by irradiating and the problem of microwave enhanced mass transport in solids remains one important issue in microwave processing of materials [28-30]. In this sense, the study of the effect of a microwave irradiation on polymeric 
membranes might contribute to the development of novel membranes.

The purpose of this paper is to investigate the influence of a microwave irradiation on a Nafion membrane. The frequency of the radiation used in this work is $2450 \mathrm{MHz}$. The selection of this frequency obeys the increasing usage of devices that are emitting in the microwave region and the industrial application of radiofrequency signals. Due to their importance in direct methanol fuel cells, swelling and hydraulic permeation properties in water and methanol media in Nafion membranes under microwave irradiation effects have been studied. Since water is also known to assist the mass transport of alcohol and oxygen in a fuel cell, the liquid uptake measurement could serve as a quantitative measure of membrane performance for a direct alcohol fuel cell application as well. Moreover, the hydraulic permeation coefficient is very important in those pressure-driven membrane processes which operate in dead-end mode and the stream of the feed flows vertically toward the membrane surface.

\section{EXPERIMENTAL}

\subsection{Materials}

A commercial Nafion 117 membrane was used in this study. The Nafion 117 membrane, from Dupont de Nemoure, USA, with a nominal equivalent weight of $1100 \mathrm{~g} / \mathrm{eq}$ and $0.183 \mathrm{~mm}$ thick, is a homogeneous cation-exchange membrane consisted of a polytetrafluoroethylene backbone and long fluorovinyl ether pendant side chains regularly spaced, terminated by a sulfonate ionic group. After polymerization, the sulfonyl fluoride is hydrolyzed and ion exchanged to produce the perfluorosulfonic acid. Although Nafion membrane is mechanically strong, there are no crosslinks between the polymers. Membrane was used as received, without any previous pre-treatment.

Pure proanalysis-grade methanol and pure water (deionized, doubly distilled, doubly filtrated, and degassed) were used.

\subsection{Irradiation Procedure}

The microwave experimental setup is presented in Figure 1. It consists of a microwave power generator, a power amplifier, a directional coupler and a GTEM chamber. The generator provides the $2450 \mathrm{MHz} \mathrm{CW}$ in a power range up to $15 \mathrm{dBm}$, that is applied via the amplifier, suitable biased by the DC power supply, to the $10 \mathrm{~dB}$ coaxial directional coupler. This setup contains the directional coupler mounted as it is shown in Figure 1, to irradiate the sample and measure the irradiation power level simultaneously. The dry samples were placed over a XPS holder inside the 250 GTEM chamber to ensure uniform electric field. Table 1 shows the two power levels and the different irradiation times considered in this work.

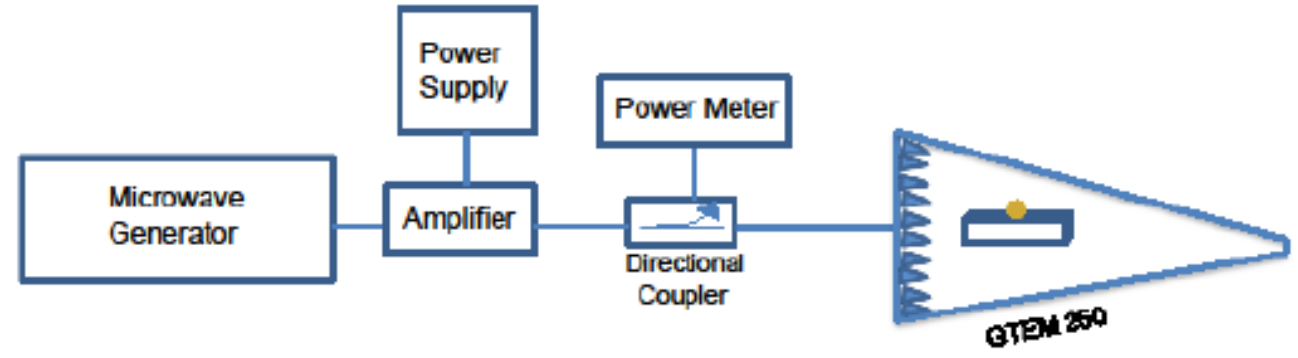

Figure 1: Microwave experimental setup.

Table 1: Power and Exposure Time of the Microwave Irradiation Used in the Different Nafion Samples Used in the Present Study

\begin{tabular}{|c|c|c|}
\hline Membrane & Power (W) & Exposure Time (s) \\
\hline \hline NR & 0 & 900 \\
\hline B1 & 0.5 & 1800 \\
\hline B2 & 0.5 & 900 \\
\hline A1 & 1.0 & 1800 \\
\hline A2 & 1.0 & 0 \\
\hline
\end{tabular}




\subsection{Liquid and Swelling Measurements}

The liquid uptake properties of the membranes investigated were studied by the usual gravimetric method. The dried membrane samples were firstly weighted. After that, the samples were immersed in a closed bottle containing the corresponding liquid and allowed to equilibrate at $25{ }^{\circ} \mathrm{C}$. To this purpose, the close bottle was placed in an oven thermostated at this temperature. After $48 \mathrm{~h}$ of immersion, the swollen membranes were taken out of the solutions, wiped carefully with filter paper and weighted again. The increase in weight was equal to the weight of the liquid sorbed by the membrane. The liquid uptake percentage, $S(\%)$, was calculated from the weight of the swollen and the dry membrane samples according to the expression:

Liquid Uptake $(\%)=\frac{m_{w}-m_{d}}{m_{d}} \cdot 100$

where $m_{w}$ and $m_{d}$ are the masses of the swollen and dry membrane, respectively.

To determine the swelling ratio of the membranes, circular membrane samples were used. The parameter considered to estimate the dimensional change of the membranes was the diameter of the samples. The diameter of the dried sample films was previously measured by using a cathetometer with $\pm 0.05 \mathrm{~mm}$ sensitivity. Afterwards, the samples were immersing in a closed bottle containing the corresponding liquid and allowed to equilibrate at $25^{\circ} \mathrm{C}$. After $48 \mathrm{~h}$ of immersion, the swollen membranes were taken out of the solutions and the diameter of the wet membrane samples was measured. The diameters of the wet and dry membranes were measured several times. The swelling ratio can be estimated from the change of the diameter samples as follows:

Swelling Ratio $(\%)=\frac{d_{w}-d_{d}}{d_{d}} \cdot 100$

where $d_{w}$ and $d_{d}$ are the average diameters of the swollen and dry membranes, respectively.

\subsection{Permeation Measurements}

The liquid permeation flux through the membranes was determined by using an experimental setup reported elsewhere [33]. Basically, the main part of the experimental device was a cell, which consisted of two equal glass chambers. The membrane with an effective surface area of $1.98 \mathrm{~cm}^{2}$ was mounted in a Teflon holder, which was positioned between the two changers. The volume of each container was about $125 \mathrm{~cm}^{3}$. The right chamber was connected to an air reservoir and to a digital pressure gauge. The pressure in this chamber was varied over the atmospheric pressure, thus the reading of the pressure gauge give the pressure difference between the two chambers. When the system was stabilized at the selected temperature, the right chamber was pressurized up to the desirable pressure value. The pressure pulses were generated with pure pressurized air through a double pressure reducer. Pulses up to 0.6 bar were applied in this half-cell. The low pressure half-cell was always kept at atmospheric pressure. The pressure difference was also measured with a mercury barometer with $0.01 \mathrm{psig}$ resolution.

For each pressure difference, the measurement consisted of following the displacement of the liquid meniscus in a L-shaped capillary tube introduced into the left chamber, as a function of time. All the permeation experiments were carried out under isothermal conditions at $25^{\circ} \mathrm{C}$. Temperature requirements were achieved by immersed the whole cell in water that was maintained at the selected temperature.

\section{RESULTS AND DISCUSSION}

\subsection{Liquid Uptake and Swelling Ratio}

Figures 2 and 3 show the results obtained for the liquid uptake and the swelling ratio, respectively, with water and methanol for the unmodified Nafion and the different irradiated membranes. In all cases the error was lower than $1 \%$.

For all the membranes, methanol uptake is about twofold higher than the water uptake, in agreement with other results reported in the literature $[2,10]$. This behavior must arise from differences in the interaction of these two classes of liquids with Nafion [2,34-36].

As can be observed in Figure 2, differences in liquid uptakes for unmodified Nafion and the different irradiated membranes were hardly observed. With both, water and methanol, a slight decrease of the liquid uptake is observed when the membrane is irradiated with the lowest power, but the differences are within the experimental error. Thus, the liquid uptake would be considered practically independent of the irradiation dose for the studied samples. 


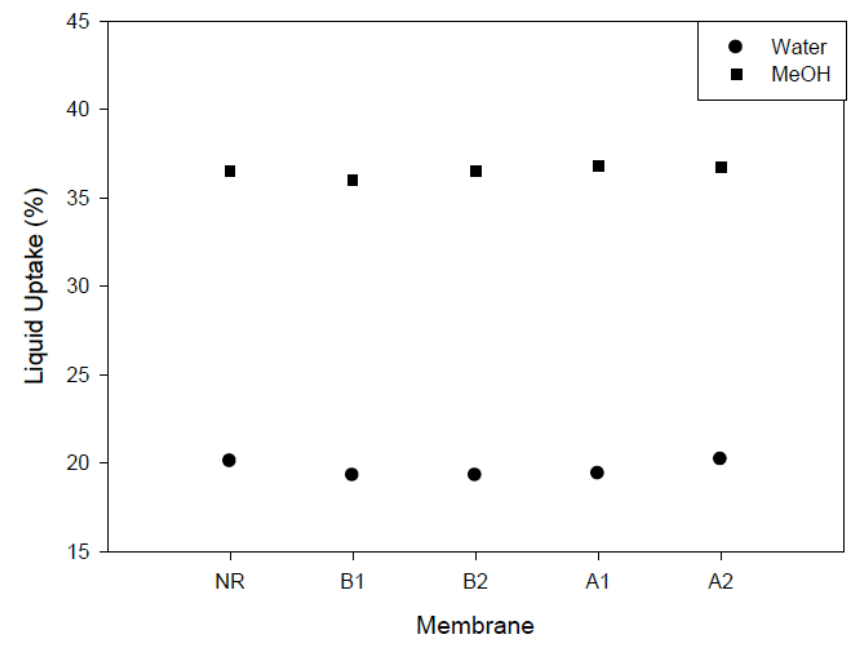

Figure 2: Liquid uptake with water and methanol for the unmodified Nafion and the irradiated membranes. Error lower than $1 \%$.

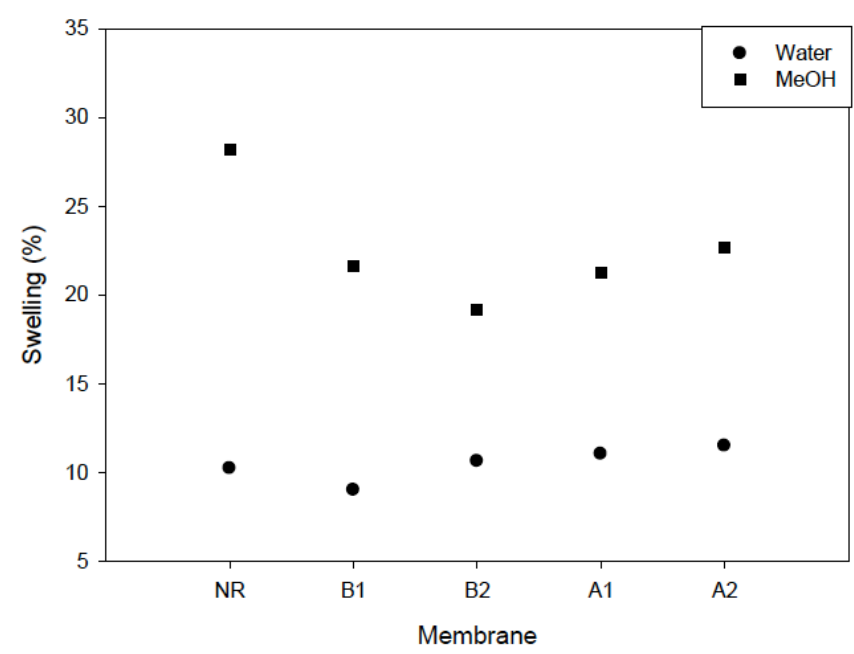

Figure 3: Swelling ratio with water and methanol for the unmodified Nafion and the irradiated membranes. Error lower than $1 \%$.

The results in Figure $\mathbf{3}$ show a general behavior for the swelling ratio similar to those described for the liquid uptake. The values corresponding to methanol are also about twofold higher than the water in agreement with results reported elsewhere [3]. Some anisotropy of dimensional change was observed, mainly with methanol, in agreement with results found in the literature $[3,37]$, probably due to the orientation of polymer chains toward the drawing direction [3]. In this case, the highest diameter was selected in order to determine the swelling ratio. However, the influence of the irradiation on the swelling ratio is higher than on the liquid uptake. In this case, the irradiation also makes the swelling ratio of the membrane decreases, and afterwards an increase is observed when the irradiation power level increases. The value for membrane $A 1$ is slightly higher than for membrane B2, despite of the absorbed energy was the same. The power of the irradiation for B2 membrane, $0.5 \mathrm{~W}$, was lower than for A1 membrane, $1.0 \mathrm{~W}$. It indicates that both the power and the total energy, and thus the exposure time, are parameters to take into account to study the effect of the irradiation on the membrane swelling.

The different behavior for liquid uptake and swelling ratio with water and methanol may be explained on the basis of the Nafion morphology. The molecules of methanol could occupy the regions close to hydrophobic polymer chains not available to water. Water interacts specifically with the sulfonic acid residues. The high level of swelling by dry alcohols involves interactions with the fluoroether side chain and cause structural change in the membrane [2]. Studies about Nafion morphology seem to indicate that it is a microphase separated polymer; the phase separation is driven by the interaction energy between the constituent groups. The tetrafluoroethylene backbone and perfluoroether side chain have similar solubility parameters and will by miscible, forming a continuous hydrophobic phase. The sulfonic acid groups and water have much larger solubility parameters and sill separate into a hydrophobic phase. Since the concentration of water in the hydrophobic phase is negligible, the contribution of water transport in the hydrophobic phase is also negligible, and water transport is only through the hydrophilic phase [38]. This absorbed water causes the membrane to swell and increases the volume through which water diffusion occurs. In the case of methanol, it seems that it cannot only remove and replace water but may also interact with perfluorinated vinyl ether chains, which explains the found higher methanol liquid uptake and swelling ratio. Really, the real structure of Nafion membrane still remains a matter of debate and studies. Different structural models have been proposed, but the common feature to all of the models is the presence of water-filled spaced, cavities and/or pores, inside a polymeric matrix wrapped by the sulphonate groups. The characteristic dimensions of these cavities depends on several chemical-physical parameters such as temperature and pressure. Thus, despite of Nafion membrane is a homogeneous membrane, it presents a nano-structure in which upon hydration water-filled channels and cavities appear [39]. The characteristics of these regions may vary according to the liquid nature [40]. The slight effect of the microwave irradiation in the membrane liquid uptake would indicate that the irradiation hardly affects this structure 
size, since the liquid uptake is practically the same for all the investigated membranes. However, the influence in the swelling ratio is higher, indicating that the irradiation may change the expansion properties of the membranes.

The polymer chain of Nafion does not have chemical crosslinking, but physical crosslinking. The relationship between irradiation dose and membrane liquid uptake and swelling ratio may be understand on the basis of crosslinking and degradation reactions occurred at the same time in the irradiated polymer $[18,2]$. When the membrane is exposed under the microwave irradiation the crosslinking of the amorphous areas, such as sulfonate ionic groups, and the degradation of the perfluorinated hydrocarbon backbone would occur at the same time. At the lowest dose, the crosslinking effect would be higher, and a decrease of the liquid uptake and thus, of the swelling ratio, is observed. The crosslinking reaction causes membrane shrinking. When the irradiation dose increases, the degradation effect would become higher which contributes to the membrane swelling. This would be in agreement with the behavior shown in Figures 2 and 3, which shows that the microwave irradiation doses cause similar effects on both liquid uptake and swelling ratio. This behavior is also observed with other kind of irraditation [18]. However, further work is necessary to understand the influence of the microwave irradiation in the membrane structure.

\subsection{Hydraulic Permeation}

The measurement of the volume flux through the membranes was performed as described in the experimental section. Measurements were carried out for several pressure difference values between 0 and 0.6 bar, starting with the highest pressure difference. An illustrative curve depicting the time evolution for the volume change in the left chamber, $V(t)$, is shown in Figure 4 at different pressure differences. The data correspond to the B2 membrane with water. In general, the curve has at short times a transitory followed at longer times by a steady state region, in which the volume change is a linear function of time.

The volume flow, $J$, through the membranes was estimated from the slope of the permeation curve, in the steady state region, by using the following expression:

$$
J=\frac{\mathrm{d} V}{\mathrm{~d} t}
$$

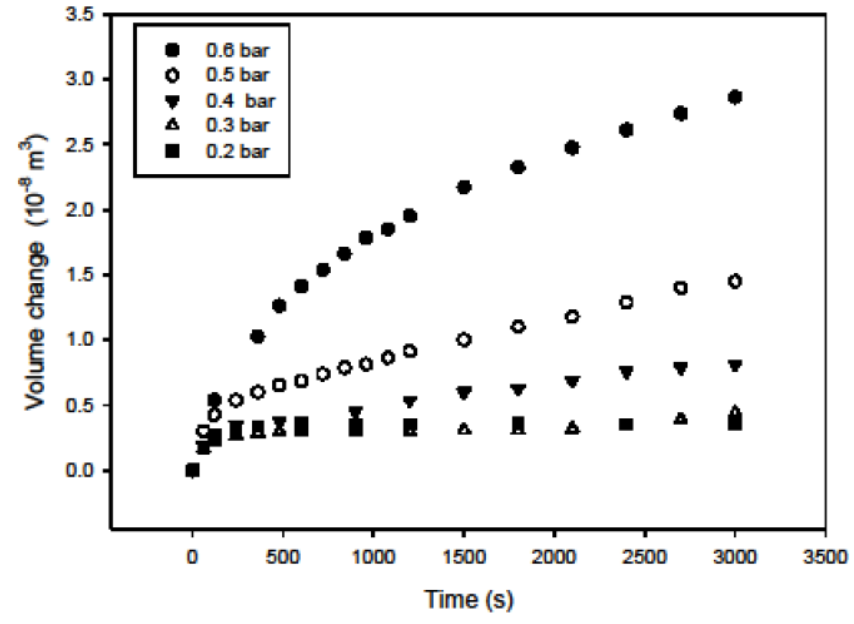

Figure 4: Volume change versus time during a permeation experiment as a function of the applied pressure difference. The data correspond to the B2 membrane with water.

The regression analysis of the data gives correlation coefficients of at least 0.99 . Figures 5 and $\mathbf{6}$ show the volume flux values of water and methanol, respectively, as a function of the hydrostatic pressure difference across the membrane for all the investigated membranes.

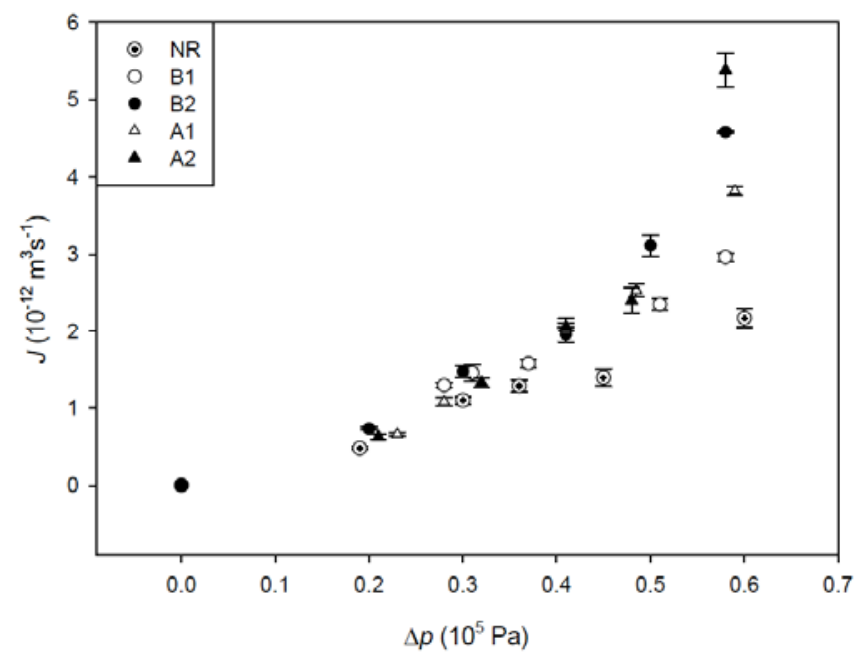

Figure 5: Water permeation volume flux as a function of the applied pressure difference for the unmodified Nafion and the irradiated membranes.

The results indicate that the obtained water fluxes are in agreement with those obtained by other authors [15] for Nafion membranes at room temperature. For the unmodified Nafion membrane, at a given pressure difference, the flux is higher for methanol than for water, in agreement to results reported elsewhere [10]. For the irradiated samples the same behavior is observed. By other hand, the influence of the irradiation becomes higher when the irradiation power increases. This trend, observed in methanol for all the pressure 
intervals, is only observed at higher pressures in the case of water. At the lower pressure differences, a major influence of the irradiation in the water flux is not observed.

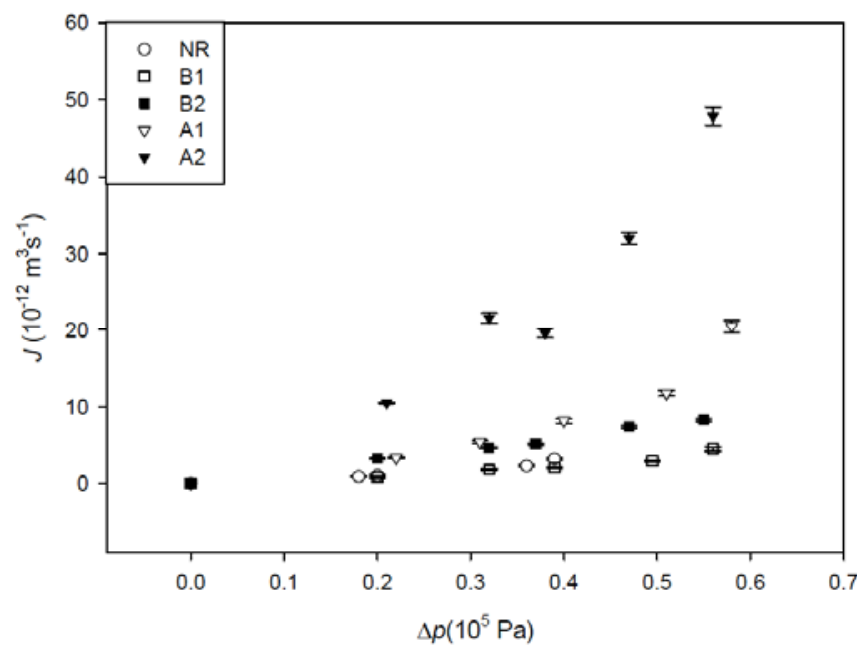

Figure 6: Methanol permeation volume flux as a function of the applied pressure difference for the unmodified Nafion and the irradiated membranes.

The analysis of data in Figures $\mathbf{5}$ and $\mathbf{6}$ shows a linear dependence between the volume flux and the hydrostatic pressure difference at low pressure differences. When the hydrostatic pressure difference increases, the behavior stops being linear. As it can be observed, the higher the irradiation dose, the lower the linear range. According to irreversible thermodynamics, the liquid volume flux dependence on the hydrostatic pressure difference can be described by the following equation [41]:

$J=L_{p} \Delta p$

where $L_{p}\left(\mathrm{~m}^{3} / \mathrm{sPa}\right)$ is the hydraulic permeability coefficient of the liquid, and $\Delta p(\mathrm{~Pa})$ is the hydrostatic pressure difference established across the membrane.

The hydraulic permeability coefficient of the liquid, $L_{p}$ can be estimated in the linear interval, according to Eq. (4). Figure 7 shows the results obtained for all the membranes, for water and methanol.

The results are in agreement with those found for water permeability of as received membranes in the $\mathrm{H}_{+}$ form by other authors [42]. It is found that the water hydrodynamic permeability coefficient is lower than those of methanol in all membranes, in agreement with the results shown in the previous section. For both liquids, water and methanol, the hydrodynamic permeability coefficient is lower for the unmodified
Nafion membrane than for the irradiated membrane samples. However, it is observed that the water hydrodynamic permeability coefficient is practically the same for all the irradiated membranes, regardless of the received irradiation intensity, whereas in the case of methanol, the hydrodynamic permeability coefficient increases if the power and/or the total absorbed energy increases.

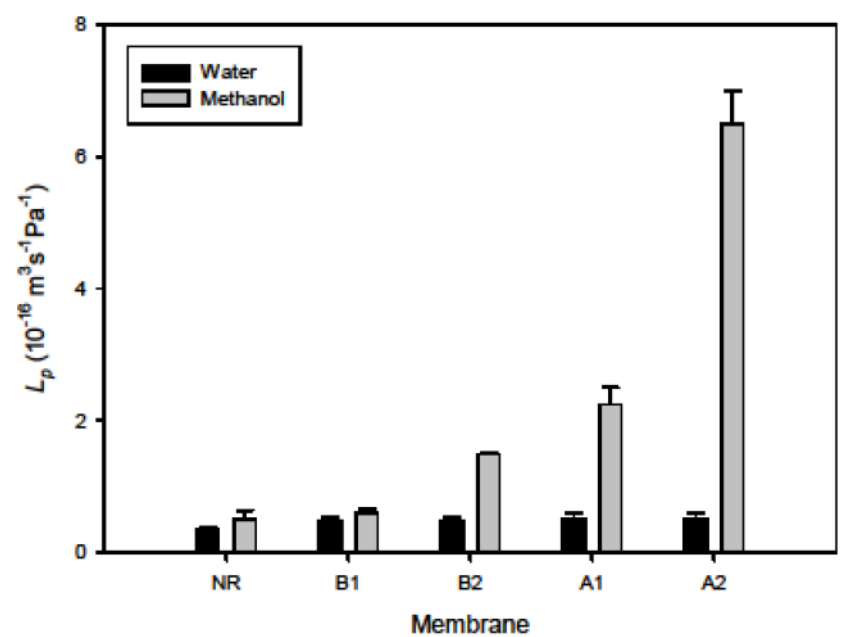

Figure 7: Water and methanol hydraulic permeability coefficients for the unmodified and irradiated Nafion membranes.

The analysis of the results shown in Figure 5-7 indicates a different behavior of the hydraulic permeation properties. The liquid hydrodynamic permeability can be correlated with the liquid content of the Nafion membrane. Thus, the higher membrane liquid uptake, the higher the hydraulic permeability $[10,43]$. This is in agreement with the results obtained for water $L_{p}$ coefficients of the irradiated membranes. In the case of water, the hydraulic permeability is practically the same for all the irradiated samples, in agreement with the results about water uptake. However, in the case of methanol, the large increase of $L_{p}$ with the irradiation dose cannot be only explained for the methanol uptake increase. We believe that the observed behavior may be due to the membrane deformation under a hydrostatic pressure difference applied which affects to the effective membrane surface exposed to the flow. Previous study has shown that polymeric Nafion membrane becomes deformed under an applied hydrostatic pressure showing the typical polymer viscoelastic behavior [44,45]. Both elastic and anelastic deformations contribute to the membrane area change. Thus, the higher the area, the higher the permeation flux. In the case of water, for the unmodified membrane a linear relationship is observed in all the pressure range. However, when the irradiation 
dose increases, the linear regime disappears at lower pressure differences. This deformation would be higher in the case of methanol. The results obtained in this work would indicate that the microwave irradiation may affect the elasticity properties of the Nafion membrane, and that this influence also depends on the permeating liquid. An estimation of the surface change would be necessary in order to determine the true hydraulic coefficient. Other possibility may be that the applied pressure modify the membrane thickness. It is known that permeabilities for liquid-liquid permeation increase with decreasing membrane thickness [46]. Further works are in progress in this sense.

\section{CONCLUSION}

The effect of a microwave irradiation on the swelling and hydraulic permeation properties of a Nafion membrane has been studied in water and methanol media. The results obtained show that both the power and the exposure time of the irradiation are parameters to take into account.

At the lowest irradiation dose, a membrane shrinking is found. However, a membrane swelling is observed when the irradiation dose increases. This behavior could be understood on the basis of crosslinking and degradation reactions occurred at the same time as a consequence of the irradiation process.

The microwave irradiation has a high influence on the membrane hydraulic permeation. The hydraulic permeability coefficient, $L_{p}$, is higher for irradiated membranes, but differences have been observed between water and methanol. With water, the effect of the irradiation is insignificant in the linear interval, and the $L_{p}$ coefficient is practically independent of the irradiation dose. With methanol, however, $L_{p}$ increases when the power or the total energy of the irradiation increase. These results may be explained by considering the degradation effect that occurs on the membrane hydrophobic matrix, which affects to the membrane elastic properties.

\section{ACKNOWLEDGEMENTS}

Financial support from Banco de Santander and Universidad Complutense de Madrid under Projects 910358 UCM Research Group-GR3/14 and 910305 UCM Research Group-GR3/14 is gratefully acknowledged.

\section{REFERENCES}

[1] Mauritz KA, Moore RB. State of understanding of Nafion. Chem Rev 2004; 104: 4535-4585.

http://dx.doi.org/10.1021/cr0207123
[2] Rivin D, Kendrick CE, Gibson PW, Schneider NS. Solubility and transport behavior of water and alcohols in Nafion. Polymer 2001; 42: 623-635. http://dx.doi.org/10.1016/S0032-3861(00)00350-5

[3] Randová A, Hovorka S, Izák P, Bartovská L. Swelling of Nafion in methanol-water-inorganic salt ternary mixtures. J Electroanal Chem 2008; 616: 117-121.

http://dx.doi.org/10.1016/j.jelechem.2007.12.018

[4] Affoune AM, Yamada A, Umeda M. Surface observation of solvent-impregnated Nafion membrane with atomic force microscopy. Langmuir 2004; 20: 6965-6968.

http://dx.doi.org/10.1021/la036329q

[5] Saarinen V, Kreuer KD, Schuster M, Merkle R, Maier J. On the swelling properties of proton conducting membranes for direct methanol fuel cells. Solid State Ionics 2007; 178: 533537.

http://dx.doi.org/10.1016/j.ssi.2006.12.001

[6] García-Nieto D, Barragán VM. A comparative study of the electro-osmotic behavior of cation and anion exchange membranes in alcohol-water media. Electrochim Acta 2015; 154: $166-176$.

http://dx.doi.org/10.1016/j.electacta.2014.12.070

[7] Heinzel A, Barragán VM. A review of the state-of-the-art of the methanol crossover in direct methanol fuel cells. J Power Sources 1999; 84: 70-74. http://dx.doi.org/10.1016/S0378-7753(99)00302-X

[8] Young SK, Trevino SF, Beck Tan NC. Investigation of the morphological changes in Nafion membranes induced by swelling with various solvents. Army Research Laboratory ARL-TR-2647 2002: 1-29.

[9] Choi P, Jalani NH, Datta R. Swelling in Nafion perfluorinated membrane: Effect of equivalent weight (EW) and polymer elasticity. The Electrochemical Society, Inc. 205th Meeting 2004; Abs. 376.

[10] Villaluenga JPG, Barragán VM, Izquierdo-Gil MA, Godino MP, Seoane B, Ruiz-Bauzá C. Comparative study of liquid uptake and permeation characteristics of sulfonated cationexchange membranes in water and methanol. J Membrane Sci 2008; 323: 421-427.

http://dx.doi.org/10.1016/j.memsci.2008.06.049

[11] Barragán VM, Villaluenga JPG, Godino MP, Izquierdo-Gil MA, Ruiz-Bauzá C, Seoane B. Experimental estimation of equilibrium and transport properties of sulfonated cationexchange membranes with different morphologies. J Colloid Interf Sci 2009; 333: 497-502. http://dx.doi.org/10.1016/i.jcis.2009.02.015

[12] Peron J, Mani A, Zhao X, et al. Properties of Nafion NR-211 membranes for PEMFCs. J Membrane Sci 2010; 356: 44-51. http://dx.doi.org/10.1016/i.memsci.2010.03.025

[13] Azher H, Scholes CA, Stevens GW, Kentish SE. Water permeation and sorption properties of Nafion 115 at elevated temperatures. J Membrane Sci 2014; 459: 104-113. http://dx.doi.org/10.1016/j.memsci.2014.01.049

[14] Kusoglu A, Karlsson AM, Santare MH. Structure-property relationship in ionomer membranes. Polymer 2010; 51: 14571464. http://dx.doi.org/10.1016/j.polymer.2010.01.046

[15] Duan $Q$, Wang $H$, Benziger J. Transport of liquid water through Nafion membranes. J Membrane Sci 2012; 392-393: 88-94.

http://dx.doi.org/10.1016/j.memsci.2011.12.004

[16] Choi WC, Kim JD, Woo SI. Modification of proton conducting membrane for reducing methanol crossover in a directmethanol fuel cell. J Power Sources 2001; 96: 411-414. http://dx.doi.org/10.1016/S0378-7753(00)00602-9

[17] Hobson LJ, Ozu H, Yamaguchi M, Hayase S. Modified Nafion 117 as an improved polymer electrolyte membrane for direct methanol fuel cells. J Electrochem Soc 2001; 148: A1185-A1190.

http://dx.doi.org/10.1149/1.1402980 
[18] Liu X, Suo C, Zhang Y, Wang X, Sun C, Li L, Zhang L. Novel modification of Nafion 117 for a MEMS-based micro direct methanol fuel cell ( $\mu$ DMFC). J Micromech Microeng 2006; 16: S226-S232.

http://dx.doi.org/10.1088/0960-1317/16/9/S09

[19] Wang X, Li X, Fu X, Chen R, Gao B. Effect of ultrasound irradiation on polymeric microfiltration membranes. Desalination 2005; 175: 187-196. http://dx.doi.org/10.1016/j.desal.2004.08.044

[20] Liu L, Ding Z, Chang L, Ma R, Yang Z. Ultrasonic enhancement of membrane-based deoxygenation and simultaneous influence on polymeric hollow fiber membrane. Sep Purif Technol 2007; 56: 133-142. http://dx.doi.org/10.1016/j.seppur.2007.01.023

[21] Kaeselev B, Kingshott $P$, Jonsson $G$. Influence of the surface structure on the filtration performance of UV-modified PES membranes. Desalination 2002; 146: 265-271. http://dx.doi.org/10.1016/S0011-9164(02)00485-X

[22] Pieracci J, Crivello JV, Belfort G. Increasing membrana permeaiblity of UV-modified poly(ether sulfone) ultrafiltration membranas. J Membrane Sci 2002; 202: 1-16. http://dx.doi.org/10.1016/S0376-7388(01)00624-X

[23] Ilconich JB, Xu X, Coleman M, Simpson PJ. Impact of ion beam irradiation on microstructure and gas permeance of polysulfone asymmetric membranes. J Membrane Sci. 2003; 214: 143-156.

http://dx.doi.org/10.1016/S0376-7388(02)00543-4

[24] Choi Y, Kang M, Kim S, Cho J, Moon S. Characterization of LDPE/polystyrene cation exchange membranes prepared by monomer sorption and UV radiation polymerisation. J Membrane Sci 2003; 223: 201-215.

http://dx.doi.org/10.1016/S0376-7388(03)00339-9

[25] Vázquez MI, Galán P, Casado J, Ariza MJ, Benavente J. Effect of radiation and thermal treatment on structural and transport parameters for cellulose regenerated membranes. Appl Surf Sci 2004; 238: 415-422.

http://dx.doi.org/10.1016/j.apsusc.2004.05.161

[26] Sionkowska A, Wisniewski M, Skopinska J, et al. Thermal and mechanical properties of UV irradiated collagen/chitosan thin films. Polym Degrad Stabil 2006; 91: 3026-3032. http://dx.doi.org/10.1016/i.polymdegradstab.2006.08.009

[27] Nagata S, Konishi Y, Tsuchiya B, Toh K, et al. Ion beam effects on electrical characteristics of proton conductive polymer. Nucl Instrum Meth 2007; B 257: 519-522.

[28] Bykov YV, Egorov SV, Eremeev AG, Rybakov KI, Semenov VE, Sorokin AA, Evidence for microwave enhanced mass transport in the annealing of nanoporous alumina membranes. J Mater Sci 2001; 36: 131-136. http://dx.doi.org/10.1023/A:1004893104413

[29] Nakai Y, Yoshimizu H, Tsujita Y. Enhanced gas permeability of cellulose acetate membranes under microwave irradiation. J Membrane Sci 2005; 256: 72-77. http://dx.doi.org/10.1016/j.memsci.2005.02.008

[30] Nakai Y, Tsujita Y, Yoshimizu H. Control of gas permeability for cellulose acetate membrane by microwave irradiation. Desalination 2002; 145: 375-377. http://dx.doi.org/10.1016/S0011-9164(02)00439-3

[31] Metaxas RC, Meredith RJ. Industrial Microwave Heating. Peter Pereginus Ltd: London; 1983.

[32] Tian ZQ, Wang XL, Zhang HM, Yi BL, Jiang SP. Microwaveassisted synthesis of PTFE/C nanocomposite for polymer electrolyte fuel cells. Electrochem Commun 2006; 8: 11581162.

http://dx.doi.org/10.1016/j.elecom.2006.05.011

[33] Barragán VM, Ruiz-Bauzá C. Streaming potential and hydraulic permeation through cation-exchange membranes. $J$ Non-Equil Thermody 1997; 22: 374-385.

http://dx.doi.org/10.1515/jnet.1997.22.4.374

[34] Skou E, Kauranen P, Hentschel J. Water and methanol uptake in proton conducting Nafion (R) membranes. Solid State Ionics 1997; 97: 333-337. http://dx.doi.org/10.1016/S0167-2738(97)00033-7

[35] Dimitrova P, Friedrich KA, Vogt B, Stimming U. Transport properties of ionomer composite membranes for direct methanol fuel cells. J Electroanal Chem 2002; 532: 75-83. http://dx.doi.org/10.1016/S0022-0728(02)01006-9

[36] Chaabane L, Dammak L, Grande D, et al. Sweelling and permeability of Nafion 117 in water-methanol solutions: An experimental and modeling investigation. J Membrane Sci 2011; 377: 54-74.

http://dx.doi.org/10.1016/j.memsci.2011.03.037

[37] Morris DR, Sun X. Water-sortion and transport properties of Nafion 117 H. J Appl Polym Sci 1993; 50: 1445-1452. http://dx.doi.org/10.1002/app.1993.070500816

[38] Chaabane L, Dammak L, Nikonenko VV, Bulvestre G, Auclair $B$. The influence of absorbed methanol on the conductivity and the microstructure of ion-exchange membranes. J Membrane Sci 2007; 298: 126-135.

http://dx.doi.org/10.1016/j.memsci.2007.04.010

[39] Plazanet M, Sacchetti F, Petrillo C, Demé B, Bartolini $P$ Torre R. Water in a polymeric electrolyte membrane: Sorption/desorption and freezing phenomena. J Membrane Sci 2014; 453: 419-424. http://dx.doi.org/10.1016/i.memsci.2013.11.026

[40] Koter S. Transport of simple electrolyte solutions through ionexchange membranes: the capillary model. J Membrane Sci 2002; 206: 201-215.

http://dx.doi.org/10.1016/S0376-7388(01)00763-3

[41] Majsztrik P, Bocarsly A, Benziger J. Water permeation through Nafion membranes: The role of water activity. J Phys Chem B 2008; 112: 16280-16289. http://dx.doi.org/10.1021/jp804197x

[42] Evans CE, Noble RD, Nazeri-Thompson S, Nazeri B, Koval CA. Role of conditioning on water uptake and hydraulic permeability of Nafion membranes. J Membrane Sci 2006; 279: 521-528.

http://dx.doi.org/10.1016/j.memsci.2005.12.046

[43] Meier F, Eigenberger G. Transport parameters for the modelling of water transport in ionomer membranes for PEMfuel cells. Electrochim Acta 2004; 49: 1731-1742. http://dx.doi.org/10.1016/j.electacta.2003.12.004

[44] Majsztrik, PW, Bocarsly AB, Benziger JB. Viscoelastic response of Nafion. Effect of temperature and hydration on tensile creep. Macromolecules 2008; 41: 9849-9862. http://dx.doi.org/10.1021/ma801811m

[45] Barragán VM, Pastuschuk E. Viscoelastic deformation of sulfonated polymeric cation-exchange membranes exposed to a pressure gradient. Mater Chem Phys 2014; $146: 65-72$. http://dx.doi.org/10.1016/i.matchemphys.2014.02.043

[46] Adachi M, Navessin T, Xie Z, Li FH, Tanaka S, Holdcroft S. Thickness dependence of water permeation through proton exchange membranes. J Membrane Sci 2010; 364: 183-193. http://dx.doi.org/10.1016/j.memsci.2010.08.011 